of Dr. Prujean, the president, appeared on the commemorative inscription. I have referred to the brotherly attachment of Harvey, Ent, and Scarburgh. Harvey's dis coveries were at length warmly accepted by foreign universities and by foreign anatomists and scholars, notably by Slegel, Bartholin, and Descartes. Some of these foreign anatomists stoutly defended Harvey's doctrines against the few remaining obscurantists who were still in opposition. His friend Thomas Hobbes said that Harvey was the only man whom he knew that had lived to see his own doctrine established in his. lifetime. Abraham Cowley's poetry is seldom read in these days, but his two poems on Harvey, based on intimate knowledge of the man and of his work, are full of genuine feeling and devotion. But the recognition most precious to him was the homage of this College. Fuller says of him he was not only Doctor Medicinae but Doctor Medicorum. The homage of the College was shown during his lifetime by the erection of his statue. It was further shown by the large gathering of fellows who followed his remains beyond the city walls in the first part of his funeral. How many of them gathered round his tomb at Hempstead in Essex we do not know. The homage of his successors in this College was shown in 1883 by the reverent removal of his remains from the damaged outer vault where they lay, to a sarcophagus in the chapel above.

Whilst we of this generation render our homage to our great benefactor let us in a few words picture to ourselves the outstanding features of his work and character.

First observe his pursuit of truth for its own sake, even though a complete solution were not forthcoming and quite independently of any ulterior benefit that might ensue. His discovery was one of those which, in Bacon's phrase, might fairly be called "light bearing" rather than "fruit yielding."

Amongst the objections which Harvey had again and again to combat in his work on the circulation was the ever-recurring question, Cui bono? Listen to his reply:

I own I am of opinion that our first duty is to enquire whether the thing be or not, before asking wherefore it is. Meantime I would only ask how many things we admit in physiology, pathology and therapeutics the causes of which are unknown to us? Whoever therefore sets himself in opposition to the circulation because if it be acknowledged he cannot account for a variety of medical opinions, nor in the treatment of diseases, give satisfactory reasons for the phenomena that appear or who regards it as in some sort criminal to call in yuestion doctrines that have descended through a long succession of ages; to all of these I reply that the facts cognisable by the senses wait upon no opinions, and that the works of nature bow to no antiquity for indeed there is nothing either more ancient or of higher authority than nature.

With what labour (he says) do we attain to the hidden things of truth when we take the averments of our senses as the guide of truth when we take the averments of our senses as the guide
which God has given us for attaining to a knowledge of his which God has given us for attaining to a knowledge of his works, avoiding that specious path on which the eyesight is dazzled with the brilliancy of mere reasoning, and so many are led to wrong conclusions to probabilities

The doctrine of "spirits" dominated the physics and the physiology of that time. Harvey says :

As it is still a question what they are, how extant in the body, of what consistency, whether separate and distinct from the blood and solids or mingled with these-upon each and all of these points there are so many and such conflicting opinions that it is not wonderful that "the spirits" whose nature is thus left so wholly ambiguous should serve as the common subterfuge of ignorance.

Persons of limited information when they are at a loss to assign a cause for anything, commonly reply that it is done by the spirits, and so they bring the "spirits" into play upon all occasions even as indifferent poets are always thrusting the gods upon the stage as a means of unravelling the plot and bringing about the catastrophe.

Harrey's demolition of the doctrine of "spirits" marks an epoch in the history of science.

Long sentences were the fashion of the time, but Harvey makes his meaning plain. He was keenly alive to the bondage of names and phrases. He was anxious to get the knowledge of things and not greatly concerned about names. He maintains that our business is not so much to inquire what a word properly signifies as how it is com. monly understood. His writings are lit up by quaint and homely similes, but they are free from the pedantry of his time. Sir Clifford Allbutt thinks he was lacking in imagination. Perhaps that is so, and $I$ think the result is that although some of his conclusions are incomplete and inadequate they contain remarkably little that is erroneous.

And about his character: There is in the opening sentences of his will a humble and definite statement of his Christian faith, and in his book on generation he expresses his conviction of the immanence of God. "He takes," Harvey says, "the right and pious view of the matter who derives all generation from the same eternal and omnipotent Deity at whose nod the universe itself depends."

Aubrey says that Harvey, like his brothers, was choleric You may say that the Treviso letters support that assertion, but remember he had great provocation, and he was a gouty subject. At all events, his choleric temper did not interfere with his courtesy and modesty in controversy, nor with generous appreciation of the work of his contemporaries. Harvey's power of concentration and detachment in biological observation in adverse surroundings was amazing. He was patient and laborious in his investigations, and reluctant to make any premature announcement of his conclusions. He was content to wait the judge ment of time and enlightenment. He grew more and more fond of contemplation and even of solitude at times, because it gave him greater opportunity for contemplation. His love of family and of friends has been already noted, and to this may fitly be added his unfailing kindness to young men and readiness to advise them as to travel and books, and his willingness to take trouble on their behalf.

The concluding parts of his last letters are very touching. The nearer he approaches the great divide the more he craves for the abiding remembrance and the affection of his correspondents. It is not only the old man eloquent, but the old man mellowed and gentle.

And now in these severe and strenuous days, when we trust that "the winter of our discontent" is soon to pass away, we recall once again the last exhortation of our great master. He bids us "ever to search out and study the secrets of Nature by way of experiment, and for the honour of our profession to continue mutual love and affection amongst ourselves."

\section{MERALGLA PARAESTHETICA}

BI

\section{W. J. RUTHERFURD, M.D., Ch.B.Glasg.,} TEMPorary LIEUTENant R.A.M.C.

Meralgia paraesthetica-a condition characterized by mononeuritis of the external cutaneous nerve of the thigh -is said to be of infrequent occurrence. In my experience, however, it has not seemed so rare when once the condition is recognized, and I have perhaps seen a dozen cases in the last ten years, five cases in soldiers having come under my care within the last nine months. The condition is important from a military point of view, because it is capable of giving rise to disability of longer or shorter duration, and this disability may be recurrent.

The condition, which occurs in both sexes, may occur with bilateral symmetry, but more commonly one limb. alone is affected. The special feature of this neuritis, which, as the external cutaneous nerve is purely sensory, is unattended by motor disturbance, is dissociated sensation, the deep or protopathic sensibility, through afferent fibres contained within the motor nerve bundles supplying the muscles, being unimpaired. Sensation over the area of distribution of the affected nerve, which, as a rule, can be strictly delimited, is lost, so far as finer sensibility is concerned, for slight touch, for perception of points, for heat and cold, and to a certain extent for pain, while deep pressure can be perceived, and a touch on the bare skin is felt as though a layer of clothing intervened, or as one might feel a touch on the back of a gloved hand. In old-standing cases a distinct cutaneous thickening may be made out locally if a fold of skin is pinched up between the finger and thumb, and the skin of the affected area (in some cases at least) begins to grow bald from atrophy of the hair follicles; while, either in association with this, or as the result of the local analgesia, the phenomenon of the cutis anserina is lost locally, so that if the patient is examined in a cold room there is no goose-skin on an area 
in the upper and outer aspect of his thigh, even though the other parts show this distinctly, with erection of the hairs over the rest of the limb.

Not only is there this anaesthesia, or rather analgesia, but perverted sensations are present in the affected area. These are variously described, and take the form of shoot. ing pains, of a sensation as though an invisible hand had grasped the thigh and were screwing round a handful of the flesh, and of a sensation as though scalding water were pouring down the outside of the limb. These sensations are usually of short duration, and are of variable onset; they may not occur for months on end, or even for years in old-standing cases, but are liable to recur again and again on little or no provocation. Their onset may be ascribed to changes in the weather, to damp and cold combined, to going out into the cold frosty night air from a warm billet, or to exercise, especially moving at the double. The pains may be nothing more than a mere tingling, or they may be so severe as absolutely to incapacitate the patient for the time being, and it is this possibility of the occurrence of sudden attacks of absolutely incapacitating pain that makes the condition of importance from the point of view of military surgery.

I have observed a patient in one of these paroxysms of pain obtain a certain amount of relief by adopting the following attitude. He bent his knee and raised the heel off the ground, flexed his body forward at the hips and seized his thigh with his hand, applying steady pressure. In this position he remained without moving for about a couple of minutes until the pain passed off, afterwards moving forward again slowly and cautiously, only to adopt the same posture a few paces further on, exercise having brought on an almost immediate recurrence of the pain.

The etiology of the condition seems to be unknown. Various more or less unsatisfying causes, including alcoholism of course, have been suggested, and the general opinion seems to be that it is probably of toxic origin.* A case is on record in which pressure of a long corset apparently induced the condition, for when a piece was cut out from that structure where it was supposed to be exerting pressure on the nerve the symptoms disappeared. One of my cases in civil practice quite distinctly occurred for the first time during involution of the uterus after childbirth, while in only one of all my cases was there any definite story of alcoholism, though even here other factors might have been at work, as the patient was a school master, who was too fat and took little or no exercise Robust and well-developed persons may suffer from this complaint; I have seen it in a man who had been an international footballer.

It seems possible, however, that the condition may owe its origin to purely mechanical causes and be dependent on the local anatomical peculiarities associated with the course of the extornal cutaneous nerve. This nerve becomes subcutaneous in the upper and outer part of the thigh by piercing one of the strongest sheets of fibrous tissues in the body, the fascia lata. Posture, as above described, seems to ease the pain during the paroxysms and exercise-the patients are convinced-to increase it or even to precipitate an attack. This must be associated with the anatomical peculiarities, and it seems feasible that the condition itself is merely caused by a nipping of the nerve trunk at its point of emergence through the fibres of the fascia lata, a possibility that will be increased in any circumstances that conduce to an overgrowth or fibrosis of that fascia. The external cutaneous is the only nerve that has this course, and in meralgia paraesthetica this nerve is alone affected.

It has been suggested to me that if this theory is correct it may be possible to relieve the condition surgically-by cutting down on the nerve, tracing it to its point of emergence through the fascia of the thigh, where this might be incised, and a flap either stitched back or excised, in order to relieve pressure on the nerve. It is a suggestion that is perhaps worth following up.

The five cases met with among soldiers are briefly described below. It is unnecessary to go into full details, as the sensory tests and the distributional area of the analgesic skin are always the same.

* A case, seemingly of this condition, is even reported as having ccurred af ter poisoning by carbon monoxide, the toxic gas that cause much trouble in mines. In this instance in tense peuralgia in th continued for fourteen days. (Huchzenmeyer, Ueber Kohlendunstcorgiftung, Inaug. dissert., Berlin, 1866.)
CASE I.-Private, aged 24; July 9th, 1915. Outside of both thighs symmetrically affected for past two days (weather at thighs symmetrically affected for past two days (weather at
present damp and overcast, and patient sleeping on the ground present damp and overcast, and patient sleeping on the ground un by a sensation as if his flesh had been gripped tightly. up by a sensation as if his flesh had been gripped tightly. ternal cutaneous nerve; on the inside of the thighs the sensation is normal.

CASE Ir.-Private, aged 22; July 19th, 1915. Pain in left thigh ; coming on acutely the previous morning and preventing sensibility is dulled. The other thigh is not affected.

CASE 1II.-Lance-Sergeant, aged 21; March 22nd, 1916. Acute pain in right thigh of four days' duration. Has never been similarly affected. Onset with aching; while walking he gets sudden stings in his thigh, causing him to stumble. While on a route march his thigh felt as though it were gripped, the sensation causing him great pain. The area of the extertal cutaneous nerve is analgesic, with a small anaesthetic point at both its upper and its lower limit. He was given phenacetin and rest; at night his thigh was so sore that he was unable to sleep for the pain. Next day be walked with a limp, and said that while he was walking sudden stinging pains shot up the thigh and caused him to stumble.

CASE IV.-Private, aged 18 years; April 5th, 1916. Bilateral, in a dirty, ill-nourished youth who has been six months in the army and who previously plucked fowls for a living. First attack was in Ireland three months ago. The pains occurred mostly when walking and in damp weather; they came and went and were sometimes worse than at others. Occasionally he had sensations as if an open knife were in his trouser pocket and had stuck into and knife were in his trousers pocket and had stuck into and lacerated the limb; at other times as if scalding water were pouring down his thigh. He distribution of the area of the affected nerve.

CASE v.-Private, aged 44 years; April 26th, 1916. Of right thigh, with pains running between his hip and knee on marching, these pains having ensued on coming out of the trenches ten days ago and having occurred daily since. When the pain comes on he is unable to use his leg, which be thinks gets quite stiff at these times; it leaves him after resting, but when he has rested and starts off again it gets very sore, and he is then has red very little. "Sometimets able to do very little. "Sometimes it is a sharp penetrating pain and at other times it is more dead-like." He had the same condition the winter before last, and was in a civil hospital for it for four weeks, being treated, he says, as a case of rheumatics. Is elderly and not well developed; locally the pain in lumbo-sacral muscles and had defective teeth.

Treatment, apart from the suggested operative interference, is of little use. 'Tonics, massage, electrical treat. ment (including the various forms of high frequency) have all been tried and have all failed. When the attacks are occurring, rest and substances such as phenacetin are indicated, while purgatives should be administered, as pressure of a loaded sigmoid in the region of the lumbar plexus is calculated to exalt the irritability of the affected nerve. Warm underclothing must be worn in all cases, as the patients are unanimous in ascribing the onset of their attacks to climatic conditions, changes of temperature, cold and damp.

The attacks of pain tend to wear off and to become less frequent with the lapse of time. The feature of the con. dition, however, is the unreliability of the symptoms and the likelihood of relapse.

\section{SHELL SHOCK AND ITS TREATMENT BY CEREBRO-SPINAL GALVANISM.}

$\mathbf{B Y}$

WILFRID GARTON, CAPTAIN R.A.M.C.

ThE term "shell shock" is made use of to describe two distinct conditions-one a severe type of traumatic neur. asthenia, and the other bearing no resemblance to a neurasthenic condition, but characterized by hysterical manifestations.

It is for shell shock of the neurasthenic type only that cerebro-spinal galvanism is of service as a treatment, for, its use being based on the assumption that neurasthenia is an organic disorder, there is no reason to expect any favourable results to follow its use in a condition of functional disorder.

In the neurasthenic type of shell shock most, if not all, of the following symptoms are found to be present: Headache (always aggravated by the advent of thundery weather), insomnia, mental depression, loss of memory, nervousness, bad dreams, fatigue (without exertion). 